\title{
Estudos e enfoques de políticas públicas no interior da universidade brasileira
}

\author{
Fabiane Maia Garcia*, Carlos Antonio de Queiroz**, Marly Alfaia Simões de Queiroz**, Ana Lúcia Vitoriano Lopes** \\ Universidade Federal do Amazonas*, Universidade do Minho**
}

\begin{abstract}
Resumo
O estudo é uma reflexão teórica desenvolvida a partir das análises de quatro pesquisas de doutoramento em educação. As ideias discutidas são parte do referencial teórico das investigações modeladas como um estudo de caso que dá primazia ao campo educativo brasileiro, com destaque para as políticas e reformas que a universidade apresenta nas últimas décadas. As pesquisas possuem como convergência a questão das políticas educativas e seus desdobramentos no interior das organizações de ensino superior sem que com isso se isolem do contexto complexo e multifacetado da qual fazem parte e onde se entrelaçam.
\end{abstract}

Palavras chave: Universidade, neoliberalismo, autonomia, avaliação, accountability.

\section{Abstract}

The study is a theoretical reflection developed from the analysis of four doctoral research in education. The ideas discussed are part of the theoretical framework of investigations modeled as a case study that gives primacy to the Brazilian educational field, especially the policies and reforms that the university has in recent decades. The surveys have convergence as the issue of educational policies and its development within higher education organizations without thereby to isolate the complex and multifaceted context to which they belong and where intertwine.

Keywords: University, neoliberalism, autonomy, evaluation, accountability.

\section{Metodologia}

O presente artigo aponta um conjunto de abordagens desenvolvidas em quatro estudos. A primeira pesquisa, já concluída, apresenta uma abordagem teórica e prática sobre a questão da democracia e a autonomia, entrelaçadas com as questões económicas globais, em que os Estados passam a apresentar políticas consideradas de certo modo comuns às agendas educativas mundiais em vigor atualmente. A segunda, aborda as políticas públicas de acesso ao ensino superior no Brasil dentro da conjuntura das políticas neoliberais. Nesse caso, há uma tentativa de compreender as mudanças na organização acadêmica, nos processos de avaliação, nas diretrizes curriculares das universidades quando atreladas ao objetivo de promover a diversificação, a diferenciação e a rápida aceleração da oferta educativa nomeadamente por meio do crescimento significativo do setor privado. O terceiro e quarto estudos são desenvolvidos no campo da administração educativa e centram suas análises nas políticas de avaliação institucional, modelos de gestão das universidades, no sentido de estudar suas influências na gestão das instituições de ensino superior com destaque para o modelo de accountability e a prática de gerencialismo que predominam no interior da universidade pública brasileira e que entram em desacordo com as formas de organizar as atividades nas universidades. Os elementos aqui dispostos correspondem ao conjunto das discussões de cada pesquisa. Desse modo, será realizado uma síntese de como cada um deles pode contribuir no processo de compreensão de temáticas importantes do ensino superior.

\section{Formas e contornos de uma autonomia}

O primeiro estudo teve como objetivo analisar as políticas e as práticas de autonomia e de democracia no cotidiano escolar. A democracia é abordada em seus aspetos históricos e conceituais que lhe apresenta como uma perspetiva global e hegemónica. A sua polissemia conceitual e de contextos suscitam uma perspetiva histórica desenvolvimentista. Esta ideia também contribuiu para o modelo democrático atual, fixado no imaginário popular, como um estágio do desenvolvimento e como uma perspetiva cíclica e histórica. Por esse prisma, a democracia representativa, como a conhecemos, assumiria a sua fase moderna e os países que a adotam, em suas distintas normas e formatos, seriam desenvolvidos.

De facto, no modelo democrático atual nem sempre é possível trilhar um percurso próprio e particular ou, ainda, os tempos históricos de cada grupo social. Ou seja, é necessário um esforço coletivo, coordenado e orquestrado, no qual as ações, nem sempre democráticas, devem estimular os povos a conhecerem e a adotarem a democracia, visão amplamente evidenciada no período da Guerra Fria. Posteriormente, o modelo democrático preponderante se efetivou a partir da fragmentação da antiga União Soviética, pois quando da sua existência, havia uma sociedade que se opunha ideológica e estruturalmente ao modelo liberal norte-americano de democracia. A quase exclusividade do modelo democrático ocidental favoreceu um cenário no qual, segundo Freire (1997), as esquerdas quase sempre na absoluta convicção de suas certezas, tornaram-se sectárias e autoritárias.

A análise das questões da democracia remeteram a uma abordagem teórica da autonomia no contexto escolar a partir da escolha de modelos de análise organizacional, nomeadamente o burocrático e o

CNPq - Conselho Nacional de Desenvolvimento Científico e Tecnológico; CAPES- Coordenação de Aperfeiçoamento de Pessoal de Nível Superior; Fundação Cearense de Apoio ao Desenvolvimento Científico e Tecnológico.

Correspondencia: Fabiane Garcia, fgarciaead@ufam.edu.br; Carlos Queiroz, carlos1queiroz@yahoo.com.br; Marly Queiroz, marly_alfaia@yahoo.com.br; Ana Lúcia, analulopess@gmail.com 
político, dessa forma são estruturadas pelo menos três formas de entender a autonomia nas organizações educativas, como no caso das universidades.

Pelas lentes do modelo burocrático, a universidade revela suas rotinas, rigidez de objetivos e metas, e também preocupação em assegurar a eficiência e a eficácia nas ações no espaço social. Nesse caso, a autonomia é vista como um disfunção que se processa como uma autonomia burocrática centralizada. Logo, a autonomia se processa em estruturas internas, em que o poder de decisão que lhe é prescrito encontra espaço para acomodar interesses divergentes entre os distintos grupos na luta pelos recursos escassos. Com essa característica de autonomia burocrática centralizada existe na universidade uma obediência normativa à legislação, aos contratos e/ou ao projeto organizacional devidamente validados e orientados pelo poder central. Para Crozier (1964, p. 186), as organizações atualmente possuem características burocráticas que têm origem em processos organizacionais complexos que também resultam de negociações entre os vários grupos sobre a maneira de impor consenso e racionalidade.

O modelo político de análise organizacional atende aos aspetos basilares da pesquisa sobre a democracia e autonomia, mas ao mesmo tempo quando "aplicado às organizações educativas, o modelo político realça-as como construções sociais, como arenas de luta e liberdade." (Estêvão, 2012, p. 186). Com essa análise foi possível perceber duas formas de autonomia, uma autonomia política desconcentrada e uma autonomia política pactuada. $\mathrm{Na}$ autonomia política desconcentrada, o repasse da responsabilidade financeira e da decisão para estruturas próximas da organização implicam, geralmente, que os docentes, os estudantes e a própria comunidade iniciem um processo de pressão para ver seus interesses postos em pauta. $\mathrm{Na}$ luta particularizada, além da dispersão das causas coletivas, há um esvaziamento dos grandes objetivos e finalidades educativas. Assim, as questões do cotidiano incendeiam a organização, as disputas internas ofuscam a relação de poder com os órgãos centrais que, por sua vez, responsabilizam a universidade, em seus grupos e indivíduos particulares, pelos fracassos nos processos avaliativos externos a que rotineiramente estão a ser submetidas. No caso da autonomia política pactuada permanece a ideia da descentralização curricular e, no caso brasileiro, sem a imposição de currículos por normativos tradicionais, organizações e sistemas educativos podem construir suas próprias propostas.

Contudo, em tal cenário ajustado aos pactos, aos acordos e aos financiamentos, tanto o sistema educativo, quanto as universidade, foram se estruturando e acoplando mais similaridades do que talvez se notasse em épocas ulteriores, quando a rigidez curricular era nitidamente percebida e imposta. Novamente, os pactos e os acordos nacionais e internacionais subsidiaram um controlo moderno, eficiente e perverso com o uso de sucessivas políticas educativas.

\section{Acesso ao ensino superior no Brasil e em Portugal}

O segundo estudo, em pleno andamento, se dedica a uma análise das políticas neoliberais no processo de acesso na educação superior do Brasil e em Portugal. Parte do pressuposto que nas últimas décadas os dois países passam por processos de redemocratização em que a educação, em especial a universitária passam a ter papel importante nesse corolário político que deve também sustentar as bases da economia neoliberal.

A discussão das realidades perpassa o tipo e o conceito de Estado, identificados em pelo menos dois tipos antagónicos: o Estado liberal, defendido pelo capitalismo, neutro e potencializador da livre iniciativa e da concorrência, e o Estado proposto por Marx, que desenvolve-se com a divisão social do trabalho e é um reflexo da base econômica da sociedade, ou seja, é a forma como a classe dominante ajusta seus interesses comuns, assegurando o seu poder.

Nos dois casos focados, há um Estado que aparece como a realização dos interesses gerais, mas na verdade é a forma pela qual a parte mais forte e poderosa ganha a aparência de interesse de toda sociedade. Desta forma, o Estado preserva o poder e a manutenção da classe dominante, dominando de forma impessoal e anônima, através das leis que fazem parecer como um poder que não pertence a ninguém. Assim o Estado se faz necessário para moderar os conflitos entre as classes antagônicas e mantê-las dentro dos limites da ordem social. Ao mesmo tempo, o Estado, ao centralizar um conjunto de recursos materiais e simbólicos, tem a habilidade da regulação do funcionamento, por meio de intervenções financeiras, dos diferentes campos. Essa intervenção pode ser feita de algumas maneiras, como por auxílios públicos e investimento no campo econômico e no campo cultural; por meio de intervenções jurídicas como as regulamentações de funcionamento de cada organização e, por último, pelo comportamento dos agentes individuais (Bourdieu, 1998).

É neste cenário que são analisadas as políticas de acesso ao ensino superior. Assim, em relação ao caso brasileiro, o estudo situa o crescimento nas matrículas da educação superior nas universidades públicas e privadas como parte das políticas de privatização do ensino superior, sustentadas pelo modelo neoliberal implantado no país. Ao mesmo tempo busca compreender a redução das matrículas em Portugal como uma realidade distinta, mas pertencente ao mesmo cenário neoliberal. Para as duas realidades sobressaem o impacto das políticas em relação as camadas menos favorecidas da população, visto que, as elites possuem este acesso facilitado pelo governo.

Para as duas realidades, a pesquisa se ocupa da análise de dados oficiais sobre o ensino superior do Brasil e de Portugal, no caso brasileiro, serão utilizados dados e informações principalmente do Instituto Brasileiro de Geografia e Estatística (IBGE), do Ministério da Educação (MEC), do Instituto Nacional de Estudos e Pesquisa Educacionais Anísio Teixeira (INEP) e da Plataforma Integrada de Gestão das Instituições Federais 
de Ensino Superior (PingIFES), onde já estão sendo analisados dados e informações sobre as modalidades de estabelecimentos de ensino superior, número de instituições de ensino superior por organização acadêmica e categoria, evolução do ensino médio para o ensino superior, número de alunos aprovados nos mais diversos tipos de seleção ao ensino superior, evolução das matrículas nas diversas modalidades de ensino superior no período compreendido entre os anos de 1993 a 2010.

No tocante a verificação da influência do neoliberalismo na educação superior há uma primazia pelo desempenho das políticas afirmativas introduzidas nos dois países com o intuito de facilitar o acesso de alunos no ensino superior. No Brasil serão tomados como análise o Programa Universidade para Todos (ProUni) que tem como finalidade conceder bolsas de estudos integrais e parciais a estudantes de graduação e de cursos sequenciais de formação específica, sempre em instituições privadas, que recebem isenção de tributos e o Fundo de Financiamento ao Estudante do Ensino Superior (FIES), cujo objetivo é financiar, na rede privada, a graduação de estudantes que não tem condições de arcar com os custos de sua formação, como pode ser observado pelas discriminações dos objetivos destas duas políticas governamentais, trata-se de financiamento da educação superior privada através de recursos públicos que vem de encontro ao objetivo deste trabalho. Em Portugal o foco serão as modificações resultantes do processo de integração europeia (Antunes, 2005) com o domínio da elaboração das políticas educativas nacionais e comunitárias situadas a partir de 2008 com o processo de Bolonha.

\section{Ensino superior no Brasil e em Portugal: uma visão a partir do accountability}

O terceiro estudo, desenvolvido na especialidade Organização e Administração Escolar, estabelece uma ligação entre os aspetos teóricos e as questões centrais que envolvem a relação universidade e accountability. Ao escolher a temática para base da análise se toma como referencia a ideia de Afonso (2012), pois para o autor algumas vezes nos enclausuramos na lógica de um pensamento único, sem lembrar que há outras alternativas e abordagens críticas que ensejem configurações mais democráticas e progressistas em relação a necessidade de se prestar contas e melhorar as formas de atendimento das demandas sociais.

Nas primeiras abordagens da pesquisa são dispostos fatos, ideias e pensamentos de referenciais brasileiros e portugueses sobre o tema: ensino superior e universidades. A análise contextualiza o cenário luso-brasileiro do ensino superior e de como se consolidou ao longo da história junto a comunidade. Dessa forma, a perspetiva apresentada reúne três momentos históricos. No primeiro, a universidade é criada como instrumento de formação de profissionais altamente qualificados e com formação geral para o desempenho de funções estratégicas e necessárias ao desenvolvimento da sociedade. Segundo Manacorda (2000) a universidade tem origem na organização das cidades em comunas, pois com o surgimento da economia mercantil deu-se concomitantemente o surgimento daqueles que repassavam seus conhecimentos aos outros e estes os seguiam como verdadeiros mestres, que faziam suas escolas sempre sob a tutela jurídica da igreja e do estado, atuando junto às escolas episcopais, e que provavelmente deram origem à Universidade.

No segundo, a universidade se consolida enquanto instituição e se aproxima da comunidade com os serviços de pesquisa e fundamentalmente de extensão. Para Nogueira (2003, p. 35), a universidade é considerada uma organização complexa não só pela sua condição de instituição especializada, mas, principalmente, pelo fato de executar tarefas múltiplas. Para o autor, cada tarefa, embora interdependente em relação às outras, possui características sui-generis o que a difere de outras organizações. Segundo o autor, a característica a mais importante da Universidade, que a sintetiza, mesmo que também esteja presente em outras organizações, é que ela é feita de pessoas para pessoas e produz bens imateriais. Do mesmo modo, o autor vislumbra outra característica da organização que, em vez de "produzir" bens de consumo, como setor secundário, ou serviços, como o setor terciário, "produz" símbolos, ideias, conhecimento, valores, etc., que, de uma maneira ou de outra, configuram e dão sentido às relações sociais e interpessoais.

O terceiro momento corresponderia ao atual, em que a universidade se vê envolvida em perspetivas mercadológicas e gerencialista. Para Carnoy (2003, p. 74) isso ocorre mediante aos financiamentos que motivavam reformas que se propunham, antes de tudo, reduzir os gastos com o ensino público: nesta versão do ajuste estrutural, a expansão da educação e o ensino de melhor qualidade se inscrevem, portanto, no âmbito de um financiamento público, restrito nessa área. Como expressão dos aspetos evidenciados no processo de globalização, as universidades passaram por um processo de expansão voltados para o atendimento das demandas e exigências da modernidade. Nesse processo de expansão do ensino superior os organismos internacionais tendem a financiar as demandas nacionais e a condicionar as formas de execução e acompanhamento das políticas de educação. Um dos mecanismos centrais difundidos internacionalmente nas reformas políticas no setor público de muitos países nos últimos anos foi o gerencialismo.

$\mathrm{Na}$ fase atual, a prestação de conta passa a ser exigida como marca de eficiência e eficácia na obtenção dos resultados esperados. Ao mesmo tempo, se observa um crescimento na perspetiva de estabelecer formas visíveis de controlo e avaliação das atividades desenvolvidas pela universidade nomeadamente a accountability. Os três momentos, ainda que vinculados aos fatos e acontecimentos, são prioritariamente marcados pela mudança na forma de ver e entender a universidade. Ao mesmo tempo correspondem aos contextos gerais com ênfase ao âmbito das instituições de ensino superior, notadamente no Brasil e em Portugal.

Nos dois cenários em análise, nomeadamente Brasil e Portugal, o processo atual de expansão do ensino superior se apresenta num cenário de crise do capitalismo 
que fortaleceu o modelo gerencial de cultura organizacional em que os princípios de gestão estratégica e do controlo de qualidade são orientados para a racionalização, a eficiência e a eficácia. Esse paradigma gerencial vem aos poucos incrementando os modelos burocráticos de gestão, trazendo consequências para as políticas sociais, especialmente no campo da educação universitária. Para Santiago, Leite, Polidori, Loréa Leite \& Sarrico (2003, p. 90) a democratização do acesso, o crescimento rápido e a diversificação da população estudantil, tornando a gestão académica mais complexa e suscitando novas conflitualidades a propósito da organização curricular e do ensino, facilitaram a emergência do discurso sobre a "cultura" da qualidade e da excelência, temas recorrentes da representação da educação, numa perspetiva de mercado ou de "quase-mercado".

Os aspetos da universidade até então abordados no estudo possibilitou caracterizar a forma como ela se apresenta junto a comunidade no processo de se aproximar e dar respostas a sociedade da qual faz parte. Inicialmente ficou evidente sua ação voltada para o ensino e formação de profissionais, pois eram necessários para ocupar funções e desenvolver atividades estratégicas na sociedade. Posteriormente, a universidade se aproxima da comunidade por suas ações de extensão e no caso brasileiro se efetivando na prestação de serviços em regiões longínquas do país. O contexto atual, de maior referência e ligação com a temática estudada, evidenciou as tendências de mercado nomeadamente a do gerenciamento, nova gestão pública e a accountability. Dado o escopo do estudo, o terceiro momento do histórico do ensino superior é certamente o de maior importância, pois estabelece uma ligação entre os aspetos conceituais discutidos e os mecanismos de controlo e avaliação, com os aspetos metodológicos e a análise de dados que seguirão.

\section{Impacto das avaliações externas na pós-graduação}

O quarto e último estudo tem como objetivo analisar a forma como os resultados das avaliações externas dos programas e cursos de pós-graduação da Universidade Federal do Ceará - UFC, durante o período de 2007 a 2012, influenciaram no desempenho da gestão organizacional.

A pesquisa é construída na perspetiva de analisar como a partir das transformações ocorridas na economia mundial, os efeitos da globalização, as lógicas da competitividade, as inovações tecnológicas e as mudanças sociais, vêm se refletindo nas organizações, em particular nas universidades, onde se configuram novas relações e práticas de trabalho, marcadas pelo signo da eficiência, da qualidade e da competitividade.

No processo de administração organizacional a criatividade e a ousadia tornam-se imprescindíveis. Assim, Fleury \& Fisher (1996) ressaltam que a inovação e a aprendizagem organizacionais devem ter intrínseca vinculação. Realidade que exige que as pessoas sejam continuamente questionadoras e aprendizes nos contextos em que se inserem face à necessidade de aprendizagem contínua como base do desenvolvimento pessoal e organizacional. Nesta linha de pensamento Silva (2004) considera que uma correta gestão de pessoal é condição fundamental para o atingir as metas organizacionais, sejam estas ligadas à docência, à investigação ou à prestação de serviços.

De maneira geral, o estudo aponta que a universidade assume características organizacionais muito próprias. Assim, Etzioni (1984) a classifica como uma organização complexa, ou seja, que resulta de um sistema diversificado e de uma estrutura organizacional com múltiplas finalidades, propiciando, na prática administrativa, um número incontável de interfaces e confrontos com seus integrantes. Ao mesmo tempo o estudo contempla abordagens que consideram a universidade enquanto organização marcada no contexto interno por contradições e tradições e, no contexto externo, por um processo de transição e mudanças.

As conceções de universidade apresentadas são postas e revistas a partir de uma perspetiva crítica em relação às novas ideias e diretrizes para mudança da universidade. Nesse novo cenário, as palavras mais frequentes são a competitividade, a produtividade, a avaliação, o controlo, a participação e a qualidade. Logo, a análise questiona a forma de administrar uma instituição de educação superior diante de tantos desafios. Um contexto que exige das Instituições Federais de Ensino Superior (IFES) respostas aos desafios como desenvolvimento científico e tecnológico, melhoria da qualidade do ensino, formação de profissionais qualificados para atendimento de demandas imediatas do mundo do trabalho, formação qualificada para inovações, preservação e desenvolvimento da cultura, pesquisa de ponta, desenvolvimento sustentável, gestão inovadora etc. Desse modo, a capacidade de atender a esses desafios comanda o futuro da universidade como instituição social necessária ao desenvolvimento de uma sociedade.

\section{Considerações finais}

As perspetivas de cada estudo apresentado correspondem aos enlaces de como as temáticas centrais em discussão podem ser percebidas no interior das universidades. Ao apresentar quatro estudos distintos, mas convergentes na análise das políticas educativas adotadas nas organizações educativas de ensino superior, há um esforço em ponderar que a universidade deve ser objetivada em suas múltiplas representações. Do mesmo modo, a sua presença nas pesquisas aponta para fatores internos e externos que tendem a alterar as práticas e políticas manifestas nessa organização. Assim, os estudos que abordam temáticas e situações distintas evidenciam um modelo de ensino superior baseado na formação para o mercado com base em um ideário neoliberal em qual se observa claramente a defesa do capital. Como marca desta realidade retomam-se conceitos como: democracia, autonomia, acesso, avaliação e accountability de modo que se possam vislumbrar outros contextos da educação superior. Estes temas se prendem a realidades e interesses distintos, mas a escolha dos mesmos é feita como um contraponto à pretensa "modernização", pois entendem que este 
cenário nada mais é do que a defesa da introdução de um modelo de educação superior baseado no neoliberalismo tendo como pano fundo a mercantilização e a mercadorização desse tipo de ensino, onde organismos multilaterais ditam os normativos e os procedimentos a serem adotados, ainda que se reconheça que não resultem necessariamente em alinhamentos uniformes e ao mesmo tempo intransponíveis as lutas e anseios por uma universidade democrática e transformadora.

\section{Referências}

Afonso, A. J. (2012). Para uma concetualização alternativa de accountability em educação. Educ. Soc., 471-48.

Antunes, F. (2005). Globalização e europeização das políticas educativas: Percursos, processos e metamorfoses. Sociologia, problemas e práticas, págs. 125-143.

Bourdieu, P. (1998). Contrafogos. Oeiras: Celta editora.

Carnoy, M. (2003). Mundialização e reforma na educação: o que os planejadores devem saber. Brasilia: UNESCO, IIPE.

Croizier, M. (1964). The bureaucratic phenomenon. Chicago: The University of Chicago Press.

Estêvão, C. V. (2012). Política \& valores em educação: Repensar a educação e a escola pública como um direito. Famalicão - Braga: Edições Húmos.
Etzioni, A. (1984). A organização moderna. São Paulo: Pioneira.

Fleury, M. T., \& Fisher, R. M. (1996). Cultura e poder nas organizações. São Paulo: Atlas.

Freire, P. (1997). Professora sim, tia não. Cartas a quem ousa ensinar. São Paulo: Olho D'Água.

Manacorda, M. A. (2000). História da educação: da antiguidade aos nossos dias. São Paulo: Cortez.

Nogueira, P. R. (2003). Tese: Gestão Estratégica Para o Estabelecimento de Estruturas Flexiveis na Universidade, Como Determinantes da Qualidade e competitividade. Florianópolis: Editora da UFSC.

Santiago, R. A., Leite, D., Polidori, M., Sarrico, C., \& Loréa Leite, M. (2003). Modelos de governo, gerencialismo e avaliação institucional nas universidades. Revista Portuguesa de Educação, 75-99.

Silva, E. A. (2004). O burocrático e o político na administração universitária. Continuidades e rupturas na gestão dos recursos humanos docentes na Universidade Agostinho Neto (Angola). Braga: Instituto de Educação e Psicologia, Universidade do Minho.

Touraine, A. (1994). O que é democracia? Lisboa: Instituto Piaget. 